\title{
A framework to test South Africa's readiness for the fourth industrial revolution
}

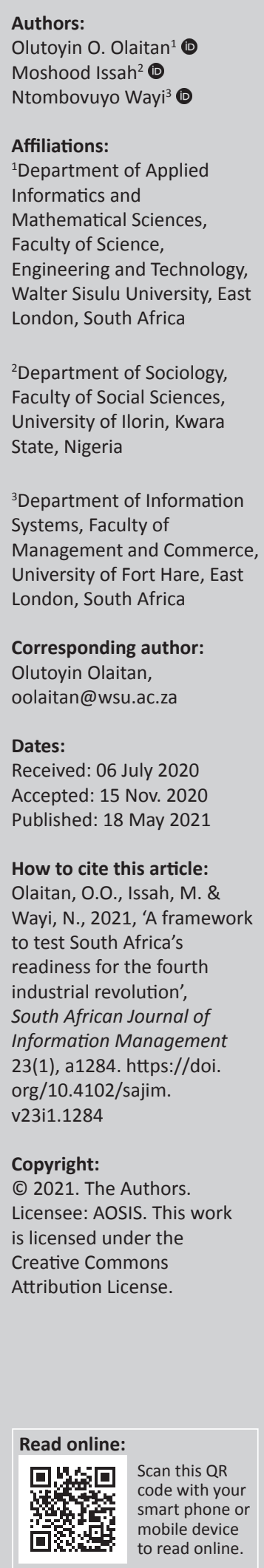

Background: The fourth industrial revolution (4IR) is being touted as having the capacity to lift South Africa out of the challenges of poverty, unemployment and inequitable distribution of wealth. However, the state of the country's readiness for the enabling technologies of the IIR is in question.

Objective: This article sought to investigate South Africa's state of readiness for the technologies that enable the 4IR. The article proposed a framework which can be used to measure the country's level of preparedness and implement the necessary processes to move the country into the 4IR era.

Method: A detailed analysis of literature was carried out on the current and futuristic technologies employed by developed countries as they moved towards the 4IR. The fit viability and the task - technology theories were employed to propose a framework to government for measuring its state of readiness for the 4IR in South Africa.

Results: Based on findings from the literature study, the article proposed the 4IR readiness framework for government to measure and subsequently plans its response to the advent of 4IR technologies in the country.

Conclusion: The framework revealed that South Africa has low technological capability, plummeting economic complexity and a fall in digital technological readiness. There is also a dearth of skilled workforce and technological infrastructure. It was recommended that government should focus on building and strengthening the resilience of both public and private institutions, investment in relevant 4IR education, infrastructural improvement, and promulgation and enforcement of legal framework to ensure security and privacy of data.

Keywords: 4IR; task - technology; fit - viability; digital technology readiness; economic complexity.

\section{Introduction}

The term 'industrial revolution (IR)' generally describes a period where technological transformations culminate in dramatic and tremendous changes in the socio-economic situation of people and countries. The global economy has passed through three major IRs. The first industrial revolution (1IR) took place between 1760 and 1840 when steam locomotive power was invented, which revolutionised textile industries in England and other developed countries. The second industrial revolution (2IR) occurred from the end of the 19th century to early 20th century with the development of electricity, mass production and division of labour. The third industrial revolution (3IR) started in the early 1950s with the development in electronics, information technology (IT) and automated production. The global economy is currently passing through the early phases of the fourth industrial revolution (4IR), which was said to have been first mentioned in the 1940s. This revolution, according to Schwab (2017), is different in that it is technologically integrating physical, digital and biological worlds; this blending will impact businesses and industry and is being referred to with catchwords such as 'industry 4.0', 'smart industry', 'intelligent industry', 'smart factory' and 'smart manufacturing'.

The adoption and usage of 4IR technologies has reached an advanced stage in developed countries, and its wave is now spreading to developing countries. It is argued that the adoption of emerging technologies under 4IR in developing countries would bring about increased production and service delivery, particularly of those products and services that are essential in contemporary society (Schwab 2017). According to Adendorff and Collier (2015), artificial intelligence (AI is a 4IR technology) would reduce the cost of goods and services, thereby making life easier for the majority. According to Cunningham (2018), 4IR has been at the vanguard of the 
transformative changes in the contemporary world; transforming the way people live as well as revolutionising, albeit radically, businesses and the industrial sector. It has the potential of catapulting digitally ready countries into unprecedented economic prosperity. It is projected that the 4IR will stimulate human-machine relationships, enhance economic growth and open up new market opportunities (Adendorff \& Collier 2015). The 4IR will make way for new talents and skills as the emergence of new technologies would change the nature of work and human relations in production.

However, it is argued that the adoption of 4IR in developing countries may not bring the expected gains if the viable resources required for its success are not present in the country. These viable resources include presence of adequate digital technologies, IT infrastrcuture as well as digital literacy. The adoption of 4IR without the presence or adequacy of viable resources is likely to worsen the economic and developmental challenges of a country. For instance, if 4IR is adopted in a country with a high level of digital illiteracy, the gains of its adoption will only go to those that are digitally literate; thereby widening the level of inequality in such a country.

Essentially, South Africa can use the potentials of 4IR to address its fundamental problems of economic recession, unemployment, poverty, inequality and deindustrialisation. The country could use the evolving technologies to industrialise, attract investment, empower its citizens and pursue inclusive growth. Nonetheless, the major concern for South Africa is that it does not seem to have adequate 'viable resources' (IT infrastructure, complex economic base, skills, digital technologies) required for the successful adoption and utilisation of new technologies required for such a 4IR-driven economy (Allen 2019). Therefore, this research article has developed a framework, based on the fit - viabilty and task - technology fit theories, for the government to measure the country's readiness (in terms of the availability of the viable resources) for 4IR. If those viable resources are unavailabe or inadequate, the article discusses remedial measures to ensure that the country benefits from the potential gains of the adoption and utilisation of $4 \mathrm{IR}$, whilst minimising its costs and uncertainties.

\section{Research problem}

Africa is bedevilled with numerous developmental challenges. Dominant amongst them are poverty and inequality (Seery, Okanda \& Lawson 2019). The level of inequality in Africa is colossal. The richest people in Africa $(0.0001 \%)$ own $40 \%$ of the wealth of the entire continent (Seery et al. 2019). Three billionaires on the African continent have more wealth than the bottom $50 \%$ of the population of Africa (about 650 million people) (Seery et al. 2019). The number of people living on less than $\$ 1.90$ a day are drastically reducing in Asia, but increasing rapidly in Africa (Seery et al. 2019). World Bank figures reveal that $87 \%$ of the world's extreme poor will be in Africa by 2030, if the current economic challenges of the continent are not addressed (cited in Seery et al. 2019). The International Monetary Fund (IMF) predicts that 24 of the $45 \mathrm{sub}$-Saharan African countries, including South Africa, are unlikely to experience a strong recovery from economic recession (Seery et al. 2019). South Africa is not exempt from the developmental challenges bedevilling the continent as the country continues to experience chronic problems of poverty, unemployment and inequality (Shivdasani 2019).

South Africa seeks to take advantage of opportunities in emerging technologies of the 4IR to address the above developmental challenges. In other words, South Africa aims to be a 'leader' in the adoption of 4IR to address its dwindling economy and current economic recession (Carew 2019). President Cyril Ramaphosa, who was appointed co-chair of the International Labour Organisation's Global Commission on the Future of Work in 2018, has established South Africa's own Presidential Commission on the 4IR. Mkentane (2019) opined that President Ramaphosa is a staunch supporter of 4IR and reiterated that South Africa has the required potential to 'become the new Silicon Valley'. Ramaphosa believes that there is an opportunity to access R5-trillion in value (roughly the size of South Africa's current gross domestic product [GDP]) over the next decade (Shivdasani 2019).

The potential of adopting the new 4IR technology to address poverty, unemployment and inequality in South Africa, however, has been questioned. Critics pointed out that the adoption and utilisation of emerging technologies will lead to significant job losses in South Africa (Adendorff \& Collier 2015; Adendorff, Lutshaba \& Shelver 2018; Adendorff \& Putzier 2018; Cunningham 2018; World Economic Forum 2017). In South Africa, estimates are that about 35\% of jobs could be replaced (Adendorff \& Collier 2015). It is also projected that more than 2 billion jobs will disappear by 2030 (Adendorff et al. 2018). Adendorff and Putzier (2018) noted that this is of particular concern to South Africa if one considers the high rate of unemployment and under-employment in the country. It is argued that any further job loss in South Africa would have severe implications on pension funds, tax revenues, GDP, employment and other social maladies. Also, the 4IR could further widen inequality in South Africa as it is likely to exclude unskilled and low-income South Africans, especially black people, women and girls (Shivdasani 2019). Friedman in OmniSA (2020) argued that South Africa may not benefit from the potentials of 4IR because of its weak economic base. He stated that the country should focus on making its economic base diverse and strong before adopting and utilising new technologies. Importantly, the adoption of new technologies will increase the number of internet users in the country, and this may expose the country and its citizens to cyber-attacks (World Economic Forum 2019). In other words, the privacy and security of internet users and the government may be at stake when 4IR is adopted and utilised.

Fortunately, the projected risks of adopting new technologies in South Africa can be averted through sound and effective national strategies on the adoption and utilisation of the $4 \mathrm{IR}$ 
(Marwala 2019). In other words, policy-makers in the country must devise sound energy, IT infrastructure and education policies to mitigate the risks and uncertainties associated with the 4IR (Adendorff \& Putzier 2018). As opined by Pretorius (2016), to avert the risk of job losses, there should be sufficient investment in training of the future workforce and retraining of the existing workforce. Similarly, Marwala (2019:2) argued that the best strategy to stay ahead of the changing needs of the labour market is to re-train, up-skill and transform the workforce'. This view was supported by Mngxati and De Haas (2019). Also, South Africa needs to develop its IT infrastructure and ensure energy security. Bankole, Osei-Bryson and Brown (2014) stressed that a sound and efficient telecommunications infrastructure is fundamental for the efficiency of the new technologies and ensuring transparency in the socio-institutional component of the 4IR. It also argued that exponential increase in digitalised technologies would require government to pay more attention to cyber security challenges, data security and privacy, amongst others (Cunningham 2018). This article sought to assess the readiness of South Africa to take advantage of the 4IR and how South Africa could measure its preparedness for the impending 4IR. The article developed a framework, based on the fit - viabilty and task - technology fit theories, to measure the readiness of South Africa to 4IR in terms of required 'viable resources'. The next section discusses the literature contextualising the 4IR.

\section{Fourth industrial revolution}

There are several technological innovations under the 4IR. However, for the purpose of this article, three of these technological innovations or components of 4IR are discussed. These are: (1) artificial intelligence, (2) internet of things (IoT) and (3) blockchains.

\section{Artificial intelligence}

Artificial intelligence is described as a system's ability to correctly interpret external data, take critical lessons from the data, and based on those lessons achieve specific goals through flexible adaptations (Kaplan \& Haenleim 2019). As such, AI gives human-like intelligence to machines or robots which allow them to carryout appropriate and intelligent decisions independently (Toor 2017). Large amounts of data can be collected and stored in the machines, which allow machines and products to interact independently of people (Adendorff \& Collier 2015). With the use of big data analytics and AI, machines are able to handle intelligent activities or tasks autonomously. The machines are equipped with sensors and store vast amounts of historical data in them. Machines and robots can perform tasks based on predefined criteria within the shortest time and at the lowest cost. Strandhagen et al. (2017) opined that AI creates machines that can make decisions and carry out actions based on the information stored in them. Such AI enables robots and machines to be analytically superior, possess superb memory, have the ability to multitask, and to recognise pattern and capacity to adapt using new self-learned information.
There is significant progress in the use and adoption of AI or machine learning, and it has been shaping socio-economic and political development of countries. Keating and Nourbakhsh (2018), Adendorff (2018), Baweja et al. (2016) were of the view that increased adoption of AI will be one of the distinctive characteristics of the 4IR. There have been some developments of AI in South Africa, notably at the University of Johannesburg, where an AI-based system that can predict the failure of transformers before they break down has been developed (Marwala 2019). This system improves efficiency and reduces costs of drawing electricity from the transformers. An AI system with the capacity to restore lost voices was also created at the same institution. In addition, AI has been used to diagnose leukaemia and to detect epilepsy in South Africa (Marwala 2019). Over and above this, AI machines that can price options and derivatives, perform credit scoring, manage portfolios, predict stock prices, estimate and price risks have been developed at the same university. Interestingly, they have also produced a machine that can predict interstate conflict (Marwala 2019).

\section{Internet of things}

Internet of Things is the interconnectedness of computing devices (both mechanical and digital machines) and the ability to transfer data over a network, without requiring human-to-human or human-to-computer interaction (Rouse 2019). The IoT is being increasingly applied in industries, and this has led to the emergence of the Industrial Internet of Things (IIoT). The IIoT is the application of IoT in manufacturing technologies (Boyes et al. 2018). It facilitates the integration of machine learning and big data technology, machine-to-machine communication and automation technology that have been utilised in industrial establishments for many years. Boyes et al. (2018) noted that the integration was facilitated by the fact that smart-machines are more efficient than human beings in terms of accurately and consistently capturing and communicating data. It brings about efficiency and innovations in the manufacturing sector.

The IoT is critical to the future of 4IR because it facilitates information-sharing (Sater 2017). The significance of IoT on the 4IR economy lies in its capacity to transform many businesses or firms into digital businesses (Adendorff \& Collier 2015). Thus, IoT will bring about new business models, improved efficiency in productivity and increased interaction between employees and customers (ed. Hung 2017). However, the major problem of IoT is that all objects are connected and communicate with each other in an unprotected network environment, which could lead to major security threats and challenges. To adopt IoT in South Africa, government must ensure digital and cyber-security; cyber-space must be properly and effectively policed and it must be safeguarded.

\section{Blockchain}

Blockchain, or distributed ledger technology is one of the disruptive and innovative technologies that has emerged in recent years. According to Miraz and Ali (2017), blockchain is 
a technological tool for ensuring transparency as ledgers (transactions) are distributed over networks, which can be verified with little involvement of the third-party. In other words, blockchain addresses the problem of trust in the economy. Deloitte (2016) argued that blockchain rewards the addition of value and ensures digital trust and automation in information-sharing between trade partners (Hackius \& Peterson 2017; Lyons 2018). Blockchain uses sophisticated cryptography to encrypt data and maintain the integrity of the ledger (Adendorff et al. 2018; Putzier 2017).

The key building blocks of blockchain are the Internet, cloud computing, Internet of things, big data and cyber-security (Ferrag et al. 2018). The blockchain technology will become a major driver in e-Health, smart energy and cities, connected and automated vehicles and advanced manufacturing. It allows a shared digital record to be maintained; hence, making it impossible for any individual to interfere with the digital record without being detected (Cunningham 2018).

\section{A review of existing frameworks for assessing a country's readiness for the fourth industrial revolution}

Schulz et al. (2018:3) cited in Cunningham, Levin and Nyakabawo (2018:13) defined readiness as the ability to capitalise on future production opportunities, mitigate risk and challenges, and be resilient and agile in responding to unknown future shocks'. In other words, readiness implies the extent to which a country has the capacity and institutional infrastructure to do the following in the future: (1) capitalise on advanced manufacturing opportunities, (2) mitigate risks and challenges, and (3) be resilient to future shocks and the unknown (Schulz et al. 2018:3). In this section, some of the existing frameworks for evaluating a country's readiness for the adoption and utilisation of 4IR are reviewed.

The first framework reviewed is the Readiness Diagnostic Model Framework developed by the World Economic Forum in collaboration with A.T. Kearney (Schulz et al. 2018). The benchmarking framework measures readiness for the future of production across two different components. These are: (1) the structure of production and (2) the drivers of production (Cunningham et al. 2018). The former represents the current baseline of production of a country, whilst the latter stands for the major enablers and propellers that give a country leverage to utilise and capitalise on the 4IR to transform its productive systems (Cunningham et al. 2018). Countries that have large and complex production infrastructures are well positioned to take full advantage of the 4IR as well as mitigate the uncertainties associated with the 4IR.

Based on this framework, South Africa is classified as a 'nascent' country with a limited production base today that exhibit low-level readiness for the future through weak performance across the drivers of production component (Schulz et al. 2018:3, cited in Cunningham et al. 2018:16). South Africa's manufacturing share of GDP has decreased to about $12 \%$ in
2020, a steady decline since the early 1990s. George Friedman, a US-based geopolitical forecaster and strategist, suggested that South Africa should focus 'on a low wage labour model and export it' (Friedman 2019). He argued that China, the USA and Japan had adopted this model to build strong and complex production infrastructures upon which the 4IR has taken off. This implies that South Africa should develop industries to absorb low and unskilled labour, and the country will earn more from exports. He noted that those countries that had followed this path of development are now at the forefront of the 4IR.

The second framework was based on the country's performance in a global technological capability index developed by Fagerberg and Srholec $(2009,2017)$. Fagerberg and Srholec $(2009,2017)$ have developed a framework to evaluate the ability of developing countries to absorb technological innovation at a high level. The framework is based on two yardsticks. These are: (1) technological capability and (2) social capability. Fagerberg and Srholec (2017) noted that technological and social capabilities are inseparable because firms need both technological development and sound socio-legal framework and environment to survive. Based on this framework, South Africa is categorised as 'falling behind technologically'. South Africa is characterised by a low initial level of technological development with below-average technological capability; hence the country is still technologically and socially unprepared for the adoption and utilisation of 4IR (Fagerberg \& Srholec 2017).

Whilst the numbers of internet users are increasing, Allen (2019) has noted that social and institutional capabilities to tackle the likely increase in cyber-attacks in South Africa are still lacking. Cyber-attacks may threaten not only banks and industry, but also human security and personal privacy. For instance, in July 2019 a major electricity provider was hit by a ransomware attack which resulted in millions being without power (Allen 2019) and in March the same year, South Africa was listed as being on a North Korean hacker's target list of cryptocurrency exchanges to be infiltrated. Allen (2019) further added that the data of 60000 South African internet users had been compromised. Allen (2019) also reported that an estimated 570 suspected cyber-attacks occur in South Africa every second. When 4IR is fully implemented, it follows that more people will come online, and the risk of cybercrimes will increase exponentially. Whilst South Africa has promulgated legislation to protect public privacy from data abuse with the Protection of Personal Information Act (2013), it is not likely to be implemented and enforced as planned in 2020, because of a dearth of technical capabilities. Also, the cybercrime and cybersecurity bill still awaits the approval of Parliament.

The third framework that was used to determine the readiness of a country for the 4IR was based on a country's performance in a global digital capability, using the Digital Evolution Index (Chakravorti, Tunnard \& Chaturvedi 2015). The index was intended to measure and evaluate the readiness of countries for the digital economy. Using this index, South 
Africa is categorised as a 'watch out country'. Chakravorti et al. (2015) argued that South Africa was and is experiencing a low level of digital development and low momentum. Thus, South Africa was failing in terms of its readiness to adopt and perform in a digital economy (Chakravorti et al. 2015). Balkaran (2016) argued in favour of closing the digital divide. This had to be addressed urgently to forestall a further widening of the socio-economic gap between the rich, digitally skilful and the poor, digitally challenged people in the society. Lack of digital technology would hamper the country's plan towards the 4IR.

Three frameworks were reviewed. The first framework, based on the structure of production and drivers of production, demonstrated that countries with a complex structure of production and strong drivers of production could be considered ready to take advantage of the full potentials of the 4IR. The second framework, based on the technological and social capabilities of countries, underlined how countries with high levels of technological and social capabilities could be considered ready to take full advantage of the 4IR. The third framework, based on digital capability, showed that countries with high digital development would be well-positioned to derive full benefits from the adoption and utilisation of 4IR. In this article, the three frameworks are integrated for holistic and critical assessment of the country's readiness and preparedness for the adoption and utilisation of the 4IR. It is against this backdrop that this article integrates the three frameworks to develop an eclectic framework based on the fit - viabilty and task - technology fit (TTF) theories.

\section{Methodology and theoretical framework}

The framework to test the readiness of South Africa for the 4IR was constructed through fit - viabilty and TTF theories and tested using relevant data derived from secondary sources such as literature and grey literature. For instance, reports of the Mail and Guardian (2019) and Business Tech (2019) amongst others, were reviewed and applied. Also, works of Kaplan and Haenlein (2019) and Rouse (2019), amongst others, were reviewed and applied to test the developed framework. The works of Adendorff et al. (2018) entitled 'Policy Implications of the 4IR for the Cultural and Creative Economy', and the work of Cunningham et al. 2018 entitled 'World Economic Forum and the 4IR in South Africa' were reviewed and applied in this study.

Through both literature and grey literature required data on: (1) available technology (artificial intelligence and blockchain); (2) Tasks of South African government (poverty, unemployment and inequality); (3) economic feasibility for adopting 4IR (such as financial health of the country); (4) organisational factors (such as the quality of the workforce and educational system of the country); and (5) availability of IT infrastructure in the country were discussed. In other words, the above data were collected through review of literature and grey literature. These data were analysed using discourse analytical technique. They were discursively reviewed and analysed.
Regarding a theoretical framework, this article draws on the fit - viability framework first proposed by Tjan in 2001, based on the fitness and viability evaluation criteria of technology performance (Liang \& Wei 2004; Liang et al. 2007) and TTF (Goodhue \& Thompson 1995; Zigurs \& Buckland 1998) that examines the readiness of South Africa to adopt and utilise the new 4IR technologies. The fit - viability model has two components: being fit for purpose and being viable. Whilst fit for the adoption of new technologies measures the degree of match between the investment in new technologies and the country's current processes and capabilities, viability refers to the likely payoff of the investment in the new technologies. For an initiative to be successful, fitness and viability must be rated highly (Liang \& Wei 2004; Tjan 2001). The adoption of new technologies will fail if the viability score is low, regardless of high fit between the technologies and tasks and vice versa. Liang et al. (2007) argued that a project that rates high on fit, but low on viability would need restructuring to improve its viability before the implementation begins. On the other hand, a project that rates high in viability and low on fit suggests that the country/organisation is prepared for implementation, but the characteristics of the task and technology lack fit. Thus for a project to be successful, viable resources must be available and the degree of fit between technology and task should be adequate and it should be evident that they can achieve the expected goals. Figure 1 below shows the interplay between fit and viability. The green quadrant is a viable quadrant that every country/ organisation must strive to attain, whilst adopting and utilising a new technology.

Essentially, the model of fit - viability was further developed with the re-conceptualisation of the TTF dimension as well as the addition of the viability dimension (Turban, Liang \& $\mathrm{Wu}$ 2011). Therefore, there are two dimensions: (1) task - technology fit dimension and (2) viability dimension. Task - technology fit dimension consists of three elements: (a) task, (b) technology and (c) fit. Task characteristics refer to the task requirements with a country/organisation. Technology characteristics refer to the attributes of the technology available, such as communication support, process structuring and information processing. Fit (task - technology fit) measures the extent to which the emerging new technologies meet the tasks requirement of the government. The second dimension is viability. This refers to the country's available resources that

\begin{tabular}{|l|l|}
\hline $\begin{array}{l}\text { High viability } \\
\text { Low fit }\end{array}$ & $\begin{array}{l}\text { High viability } \\
\text { High fit }\end{array}$ \\
\hline $\begin{array}{l}\text { Low viability } \\
\text { Low fit }\end{array}$ & $\begin{array}{l}\text { Low viability } \\
\text { High fit }\end{array}$ \\
\hline
\end{tabular}

Source: Liang, T.P. \& Wei, C.P., 2004, 'Introduction to the special issue: Mobile commerce applications', International Journal of Electronic Commerce 8(3), 7-17. https://doi.org/10.10 80/10864415.2004.11044303; Liang, T.P., Huang, C.W., Yeh, Y.H. \& Lin, B., 2007, 'Adoption of mobile technology in business: A fit-viability model', Industrial Management and Data Systems 107(8), 1154-1169. https://doi.org/10.1108/02635570710822796.

FIGURE 1: Fit and viability model. 
affect the maturation of new technologies. The dimension consists of three factors: economic, organisation and IT infrastructure. The economic factor refers to the economic feasibility of the implementation and upgrades and overall financial health of the country. The organisation factor refers to the overall readiness of the organisation/country to utilise the 4IR. The IT infrastructure assesses the country's overall information communication and technology infrastructure (see Figure 2 for diagrammatical representation of the interplay).

\section{Framework for testing South Africa's readiness for the fourth industrial revolution}

Drawing from the theoretical framework, there are two dimensions: (1) task - technology fit dimension and (2) viability dimension. These two dimensions are used to build a framework for testing South Africa's readiness for the 4IR. These are discussed below:

\section{Task - Technology fit dimension}

This dimension consists of three elements: (1) task, (2) technology and (3) fit. Task characteristics refer to the task requirements within a country/organisation. In the context of this article, tasks expected of new technologies 4IR in South Africa are: (a) stimulating economic growth; (b) improving and enhancing productivity and service delivery; (c) creating new jobs for South Africans and (d) reducing inequality amongst South Africans. In other words, the major task of the South African government is to address its chronic problems of poverty, unemployment and inequality (Shivdasani 2019). Technology characteristics refer to the attributes of the technology available such as communication support, process structuring and information processing. In the context of this article, the emerging technologies are AI (machines and robots), blockchain and internet of things

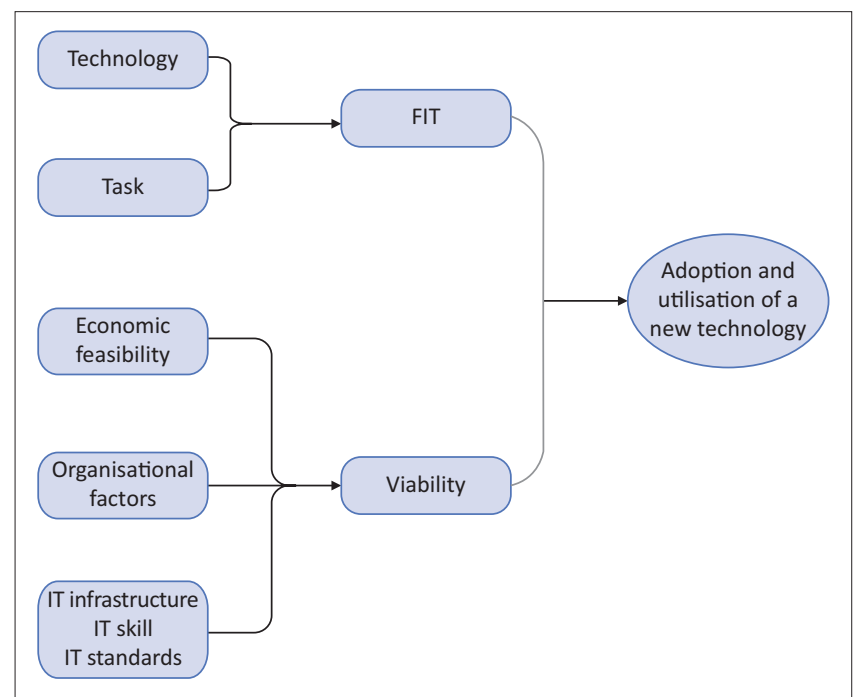

Source: Liang, T.P. \& Wei, C.P., 2004, 'Introduction to the special issue: Mobile commerce applications', International Journal of Electronic Commerce 8(3), 7-17. https://doi.org/10.10 80/10864415.2004.11044303; Liang, T.P., Huang, C.W., Yeh, Y.H. \& Lin, B., 2007, 'Adoption of mobile technology in business: A fit-viability model', Industrial Management and Data Systems 107(8), 1154-1169. https://doi.org/10.1108/02635570710822796.

FIGURE 2: Fit and viability model.
(IoT), amongst others. Calitz, Poisat and Cullen (2017) noted that robots are widely used in automotive manufacturing in South Africa. In South African industries, investment in AI started recently. In South Africa, farmers have been using drones to check wild life, livestock, fence lines, windmills and dam levels (Weeden 2016). Many South African companies have been showing interest in experimenting with AI, even though its adoption cannot be compared with advanced countries like the USA where it has been utilised for many years (Business Tech 2019).

Fit (task - technology fit) measures the extent to which the emerging new technologies meet the tasks requirement of the government. In the context of South Africa, fit measures whether emerging technologies (AI, blockchains, IoT, amongst others) can help in the tasks of addressing chronic problems of inequality, unemployment and poverty in South Africa. A study conducted by Boston Consulting revealed that automation, such as $\mathrm{AI}$ and robotics, is more likely to bring about $10 \%-30 \%$ increase in labour productivity in manufacturing industries in the next decade. It is noteworthy that the South African economy is dependent on the minerals-energy complex (MEC). It is suggested that the country needs to transform towards becoming a knowledge economy, and the process is partially reflected in the National Development Plan 2030. This is important because South Africa has experienced enormous deindustrialisation over the past three decades.

\section{Viability dimension}

This refers to the country's available resources that affect the maturation of new technologies in South Africa. The viability dimension consists of three factors: economic, organisational and IT-infrastructural ones. The economic factor refers to the economic feasibility of the adoption and implementation of the new 4IR technologies as well as the financial health of the country. The current downturn in economic growth and productivity of South Africa may affect the adoption of new technologies. In other words, the country's ability to provide financial support for the implementation of $4 \mathrm{IR}$ across industries and sectors is fundamental. In all, economic factors assess the economic stability and prosperity of the country which can impact investments, improvement and advancement in 4IR. South Africa is currently in an economic recession, so coupled with the severe economic implications of COVID-19 the country may find it difficult to invest adequately in 4IR technologies. This implies that South Africa is currently not financially viable to adopt and utilise 4IR technologies.

The organisation factor refers to the overall readiness of the country to adopt and utilise 4IR technologies. A highly skilled population will have the capability to utilise 4IR technologies (Shivdasani 2019). South Africa cannot be categorised as having a highly skilled workforce as there is still a high level of illiteracy in the country. To this end, South Africa does not have sufficient skills base to support the envisioned high level of technological innovation 
(Shivdasani 2019). The first step towards this is to develop adequate engineering and digital talents in the country's people. People who are already working and those who are still unemployed need to be trained on how to operate and manage emerging disruptive technologies.

To avert the risk of losing jobs in the era of $4 \mathrm{IR}$, Marwala (2019) stressed that the best strategy to stay ahead of the changing needs of the labour market is to retrain, up-skill and transform the workforce'. Pretorius (2016) suggested that firms across all industries and government should concentrate more on the urgent reskilling of the current workforce in order to prepare for future changes in labour needs. In achieving the goal of having a big enough skilled workforce, there is a pressing need to revolutionise the country's educational system so that it will be able to produce graduates with basic skills to deal with the disruptive effects of the new technologies in their workplaces (Adendorff \&
Putzier 2018; Mngxati \& De Haas 2019). Also, Marwala (2019) stated that the universities are crucial to the skill development of future generations in the new technological era. To this end, many universities are partnering with businesses and the private sector to develop new curriculum, and to align research programmes to solving real-world problems. Many of these higher institutions are also working to develop effective intellectual property (IP) strategies and establish dedicated technology transfer offices (TTOs) (Marwala 2019).

The IT infrastructure assesses the country's overall information communication and technology infrastructure. A country with a high level of technological development would support the 4IR. From available literature, South Africa is not considered as having adequate IT infrastructure. High-speed, low-cost and universal broadband coverage is necessary for the country to capitalise on the 4IR. Based on the reports of the Independent Communications Authority of South Africa

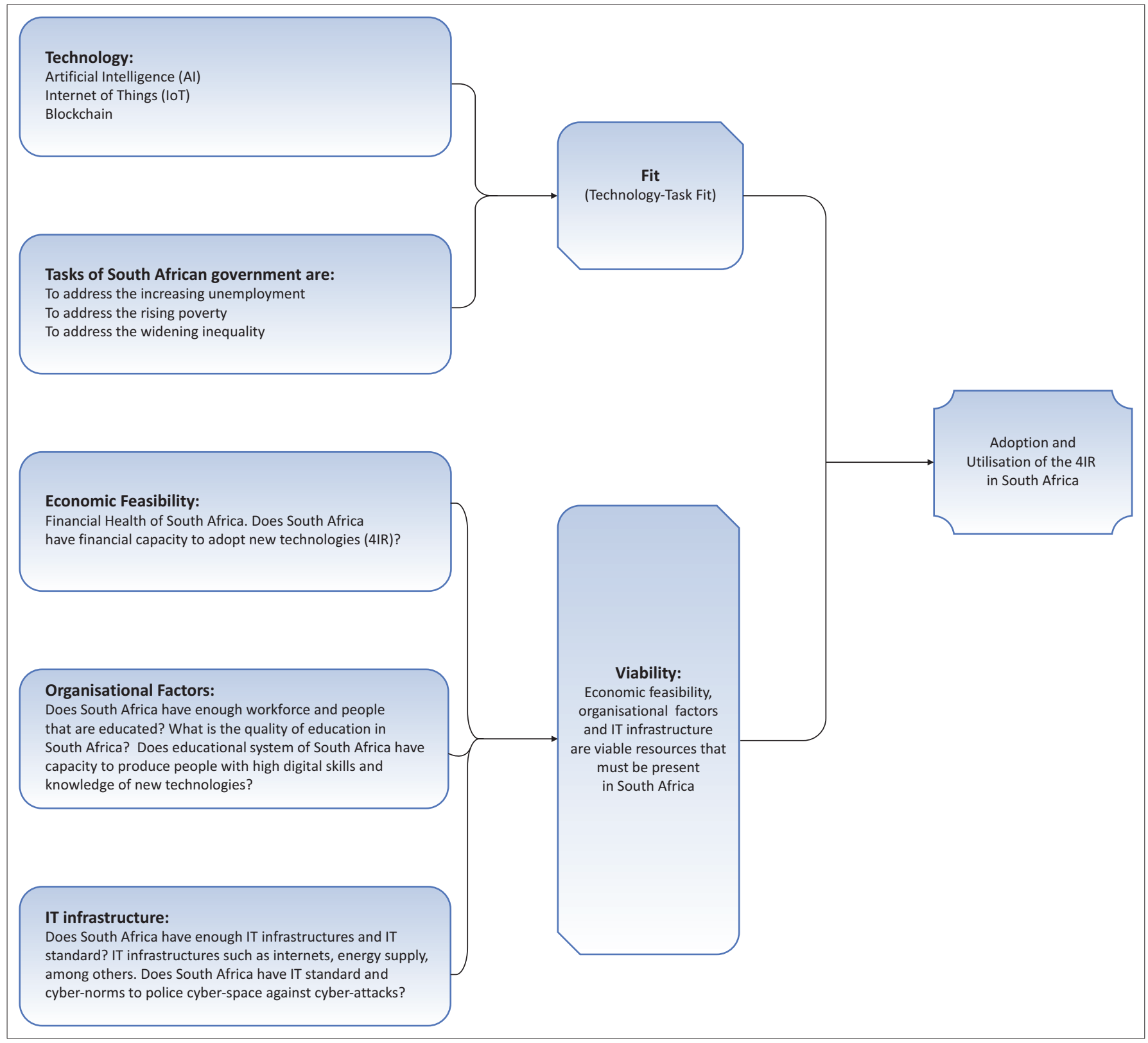

FIGURE 3: Proposed fourth industrial revolution readiness model. 
(ICASA 2016), 15\% of households have fixed broadband and close to half of the people of South Africa have smartphones, or mobile data access. Advanced IoT applications will require 5G mobile telecoms infrastructure. However, South Africa has not yet even migrated from analogue to digital terrestrial broadcasting - a move necessary to free up a valuable spectrum for rural, mobile data connectivity, thereby providing internet access to those who do not yet have it and to accelerate the path to 5G. Analogue to digital should have been completed by 2015, but 'a combination of indecisions, incompetence and possibly corruption led to successive delays' (Shivdasani 2019:2). Bankole et al. (2014) stressed that a sound and efficient telecommunications infrastructure is fundamental for the efficiency of the new technologies and ensuring transparency in the socio-institutional component of the 4IR. Also, regular supply of electricity is essential for the successful adoption of new technologies as well as to facilitate IT infrastructure. In South Africa, Eskom, the sole electricity provider, struggles to supply electricity (Du Venage 2020). Load shedding by Eskom may make it difficult for the country to adopt and utilise new technologies. Energy security is crucial for the adoption of 4IR. South Africa cannot be said to be ready when it is has not attained energy security. In view of the aforementioned facts, the 4IR readiness model is hereby proposed:

\section{Conclusion and recommendations}

The Fourth Industrial Revolution (4IR) has been spreading across countries, and many African countries have started to feel the impact in some sectors of the economy. Therefore, it is fundamental that countries should be ready and prepared for dramatic transformation in technological environments, or be ready to stagnate and fall behind other countries. South Africa has demonstrated its determination to adopt and utilise the 4IR technologies to drive knowledge or digital economy with the aim of addressing its chronic problems of poverty, unemployment and inequality. However, whilst there maybe a fit between the new technologies (artificial intelligence, internet of things and blockchain) and the tasks of building a knowledge and digitally based economy to address the above-mentioned chronic problems of South Africa, South Africa does not have adequate viable resources to maximise on the full potentials and opportunities of the 4IR and to mitigate the likely future-shocks of the 4IR technologies. In other words, South Africa has not been well positioned to take full advantage of the 4IR and cope with the uncertainties associated with the 4IR.

The above framework shows that South Africa is still having low technological capability, economic competency is plummeting and there is a fall in digital technological readiness. South Africa seems not to have the financial wherewithal to finance the adoption and utilisation, plus the adoption of new technologies given its current economic state, coupled with the adverse economic implication of COVID-19. Also, South Africa does not have enough digitally skilled workers to manage and operate the new technologies. In addition, South Africa is lacking IT infrastructure and energy security. Based on these lapses and inadequacies, it is suggested that:

Government should focus on ensuring coordination in the public and private sectors, as well as between them. Coordination in/between public and private sectors would produce the required synergy to promote innovations. To ensure coordination, resilience of both the private and public sectors must be built and strengthened by the government. This is achievable through sound, appropriate and effective economic policies that would engender economic development and innovative thinking. It is vital for the government to grow the economy and it must ensure that it is an inclusive growth. Both public and private sectors should be encouraged and trained to initiate and develop new business models in order to revolutionise production processes. Key stakeholders should be identified and engaged to identify various enablers that could help in deriving the benefit of the 4IR.

Government should develop digital skills of the citizens through futuristic educational curriculum. It must be ensured that the current curriculum for higher education directly addresses the learning outcomes for those who would take up employment, and others who would be entrepreneurs in the emerging digital space driven by the 4IR. Digital illiteracy and language barriers need to be addressed if South Africa is to achieve its goal of benefitting from the 4IR. It is important to re-skill the majority of the citizens so that they will be equipped to use and apply emerging digital devices. In other words, the number of indigenous IT professionals should be increased for the successful adoption of the 4IR technologies.

The promulgation and enforcement of legal framework to police digital space is fundamental. Legal aspects are needed to ensure security and privacy of data. Laws must be in place to monitor, regulate and penalise unprofessional and unethical behaviour in the digital space. One of the major threats of adopting $4 \mathrm{IR}$ is the likelihood of increase in cyber-attacks. However, with effective laws in place, coupled with trained personnel that would be exercised with the responsibility of policing the cyber space, the level of cyber-attacks will be checkmated.

There is a need for the development of physical infrastructure, particularly digital infrastructure and other supportive infrastructure. Along with the internet backbone, there should be adequate fixed broadband, mobile telecommunications, communications satellite, network infrastructure, data centres, cloud computing, platforms amongst others. Also, other supporting infrastructure such as uninterrupted electricity should be provided. Importantly, government should facilitate and enable access to ICT and connectivity. Also, data prices should be made affordable for the poor because the majority of South Africans are currently unable to afford data costs. 


\section{Acknowledgements Competing interests}

The authors declare that they have no financial or personal relationships that may have inappropriately influenced them in writing this research article.

\section{Authors' contributions}

O.O.O. and M.I. lead authors and writing up of article. N.W. further improved the article.

\section{Ethical considerations}

This article followed all ethical standards for research without direct contact with human or animal subjects.

\section{Funding information}

This research received no specific grant from any funding agency in the public, commercial or not-for-profit sectors.

\section{Data availability}

The authors confirm that the data supporting the findings of this study are available within the article.

\section{Disclaimer}

The views and opinions expressed in this article are those of the authors and do not necessarily reflect the official policy or position of any affiliated agency of the authors.

\section{References}

Adendorff, C. \& Collier, D., 2015, An umbrella for the rainbow nation: Possible futures for the Republic of South Africa towards 2055, 1st edn., Alfresco Graphics, Port Elizabeth.

Adendorff, C., Lutshaba, U. \& Shelver, A., 2018, Readiness of private and public sector South Africa for the 4IR, Nelson Mandela Business School, Port Elizabeth.

Adendorff, C. \& Putzier, M., 2018, A causal layered analysis of South Africa's readiness for the fourth Industrial Revolution towards 2035, pp. 54-66, s.n., Port Elizabeth.

Allen, K., 2019, Africa should not be too quick to embrace the fourth industria revolution, s.n., Johannesburg.

Balkaran, S., 2016, The fourth industrial revolution - Its impact on the South African public sector, s.n., Cloudfront.net.

Bankole, F.O., Osei-Bryson, K.M. \& Brown, I., 2014, 'The impacts of telecommunications, infrastructure and institutional quality on trade efficiecy in Africa', Information Technology for Development 21(1), 29-43. https://doi.org/10.1080/02681102. 2013.874324

Baweja, B., Donovan, P., Haefele, M., Siddiqi, L. \& Smiles, S., 2016, Extreme automation and connectivity: The global, regional and investment implications of the fourth industrial revolution, World Economic Forum, s.I.

Boyes, H., Hallaq, B., Cunningham, J. \& Watson, T., 2018, 'The Industrial Internet of Things(IloT): An analysis framework', Computers in Industry 101, 1-12. https:// doi.org/10.1016/j.compind.2018.04.015

Business Tech, 2019, How Al is being used in South Africa, viewed n.d., from https:// businesstech.co.za/news/enterprise/322505/how-ai-is-being-used-in-southafrica/.

Calitz, A.P., Poisat, P. \& Cullen, M., 2017, 'The future African workplace: The use of collaborative robots in manufacturing', SA Journal of Human Resource Management/SA Tydskrif vir Menslikehulpbronbestuur 15, a901. https://doi. org/10.4102/sajhrm.v15i0.901

Carew, J., 2019, Digital skills are Africa's ticket to prosperity, viewed n.d., from https:// www.itweb.co.za/content/RgeVDMPomYz7KJN3.

Chakravorti, B., Tunnard, C. \& Chaturvedi, R.S., 2015, 'Where the digital economy is moving the fastest', Harvard Business Review 19, 1-7.
Cunningham, S., 2018, World economic forum and the fourth industrial revolution in South Africa, Department of Trade and Industry, Pretoria.

Cunningham, S., Levin, S. \& Nyakabawo, W., 2018, World economic forum and the industrial revolution in South Africa, Department of Trade and Industry, Johannesburg

Deloitte, 2016, Industry 4.0: Is Africa ready for digital transformation?, viewed n.d., from http://www.deloitte.com/content/dam/deloitte/za.

Du Venage, G., 2020, 'South Africa comes to a standstill with Eskom's load shedding', Engineering and Mining Journal 221(1), 18.

Fagerberg, J. \& Srholec, M., 2009, 'Innovation systems, technology and development: Unpacking the relationships', in B.A. Lundvall, K.J. Joseph, C. Chaminade \& J. Vang (eds.), Handbook of innovation systems and developing countries building domestic capabilities in a global setting, pp. 83-115, Edward Elgar Publishing Inc, Cheltenham.

Fagerberg, J. \& Srholec, M., 2017, 'Capabilites, economic development and sustainability', Cambridge Journal of Economics 41(3), 905-926. https://doi. org/10.1093/cje/bew061

Ferrag, M.A., Derdour, M., Mukherjee, M., Derhab, A., Maglaras, L., Janicke, H. et al., 2018, 'Blockchain technologies for the internet of things: Research issues and challenges', IEEE Internet of Things Journal 6(2), 2188-2204. https://doi. challenges', IEEE Internet of
org/10.1109/JIOT.2018.2882794

Friedman, G., 2019, 'Is South Africa really ready for the 4th industrial revolution?', Financial Mail, 05 July 2019, p. 1, 4IRSA Digital Economy Summit, Johannesburg.

Goodhue, D.L. \& Thompson, R.L., 1995, 'Task - Technology fit and individual performance', MIS Quarterly 19(2), 213-236. https://doi.org/10.2307/249689

Hackius, N. \& Peterson, M., 2017, Blockchain in logistics and supply chain: Trick or treat, pp. 1-17, HICL, Hamburg.

Hung, M. (ed.), 2017, Leading the loT: Gartner insights on how to lead in a connected world, Gartner Group, Stamford, CT.

ICASA, 2016, Annual report, viewed 16 December 2019, from www.icasa.org.za/ pages/annual-reports.

Kaplan, A. \& Haenleim, M., 2019, 'Siri, Siri, in my hand: Who's the fairest in the land? On the interpretations, illustrations, and implications of artificial intelligence', Business Horizons 62(1), 15-25. https://doi.org/10.1016/j. bushor.2018.08.004

Keating, J. \& Nourbakhsh, I., 2018, 'Teaching artificial intelligence and humanity', Communications of the ACM 61(2), 29-32. https://doi.org/10.1145/3104986

Liang, T.P., Huang, C.W., Yeh, Y.H. \& Lin, B., 2007, 'Adoption of mobile technology in business: A fit-viability model', Industrial Management and Data Systems 107(8), 1154-1169. https://doi.org/10.1108/02635570710822796

Liang, T.P. \& Wei, C.P., 2004, 'Introduction to the special issue: Mobile commerce applications', International Journal of Electronic Commerce 8(3), 7-17. https:// doi.org/10.1080/10864415.2004.11044303

Lyons, T., 2018, Blockchain innovation in Europe, European Union Blockchain Observatory \& Forum, s.l.

Mail \& Guardian, 2019, 4IR and South Africa's readiness to embrace it, viewed 23 December 2019, from https://mg.co.za/article/2019-10-18-00-4ir-and-southafricas-readiness-to-embrace-it/.

Marwala, T., 2019, Preparing Africa for the fourth industrial revolution, WIPO magazine, Johannesburg.

Miraz, A. \& Ali, M., 2017, 'Applications of blockchain technology beyond crytocurrency', Annals of Emerging Technologies in Computing 2(1), 1-6. https://doi. org/10.33166/AETiC.2018.01.001

Mkentane, L., 2019, Ramaphosa eyes Silicon Valley in South Africa, viewed n.d., from https://newsexpressngr.com/news/78454-Ramaphosa-eyes-Silicon-Valley-inSouth-Africa.

Mngxati, V. \& De Haas, J., 2019, Unlocking digital value for business and society in South Africa, Accenture, Johannesburg.

Omnisa, 2020, Is South Africa ready for the fourth industrial revolution, viewed 10 July 2019, from https://www.omniaccounts.co.za/articles/is-sa-ready-for-4thindustrial-revolution.

Pretorius, T., 2016, Fourth industrial revolution: Promise or peril?, viewed n.d., from http://www.leader.co.za/article.aspx?s=6\&f=1\&a=6256.

Putzier, M.L., 2017, 'The readiness of the South African private and public sector for the 4IR', Masters thesis, Nelson Mandela University.

Rouse, M., 2019, IoT devices (internet of things devices), viewed n.d., from https:// internetofthingsagenda.techtarget.com/definition/loT-device.

Sater, S., 2017, Blockchain and the European union's general data protection regulation: A chance to harmonise international data flows, viewed nd., from https://doi.org/10.2139/ssrn.3080987.

Schulz, O., Aurik, J., Zuazua, M. \& Blaylock, A., 2018, Readiness for the future of production, World Economic Forum, Geneva.

Schwab, K., 2017, The fourth industrial revolution: What it means and how to respond, viewed 23 August 2019, from https://www.weforum.org/agenda/2016/01/thefourth-industrial-revolution-what-it-means-and-how-to-respond/\#.

Seery, E., Okanda, J. \& Lawson, M., 2019, Oxfam.Org., viewed 13 December 2019 from https://www-cdn.oxfam.org/s3fs-public/file_attachments/bp-tale-of-twocontinents-fighting-inequality-africa-030919-en.pdf.

Shivdasani, A., 2019a, South Africa's foray into the fourth industrial revolution: Let's learn to walk before we try to fly, viewed n.d., from https://www.dailymaverick. co.za/opinionista/2019-07-24-south-africas-foray-into-the-fourth-industrialrevolution-lets-learn-to-walk-before-we-try-to-fly/. 
Shivdasani, A., 2019b, South Africa's foray into the fourth industrial revolution: Let's try to walk before we fly, viewed n.d., from https://www.dailymaverick.co.za/ opinionista/2019-07-24-south-africas-foray-into-the-fourth-industrial-revolution-
lets-learn-to-walk-before-we-try-to-fly/.

Strandhagen, J.W., Alfnes, E., Strandhagen, J.O. \& Vallandingham, L.R., 2017, 'The fit of industry 4.0 applications in manufacturing logistics - A multiple case study', Advanced Manufacturing 5, 344-358. https://doi.org/10.1007/s40436-017-0200-y

Tjan, A.K., 2001, 'Finally, a way to put your internet portfolio in order', Harvard Business Review 79(2), 76-85.

Toor, M.J., 2017, 'Industry 4.0 as smart enabler for innovative business models', Journal of Business Research Transformation 1(1), 1-22.
Turban, E., Liang, T.P. \& Wu, S.P.J., 2010, 'A framework for adopting collaboration 2.0 tools for virtual group decision making', Group Decision and Negotiation 20 , 137-154. https://doi.org/10.1007/s10726-010-9215-5

Weeden, N., 2016, Drone use for precision agriculture in South Africa, viewed 13 August 2019, from https://ccainsurance.co.za/drone-use-for-precisionagriculture-in-south-africa/.

World Economic Forum, 2019, 'The global risks report 2019', Computer Fraud \& Security 2019(2), 4. https://doi.org/10.1016/S1361-3723(19)30016-8

Zigurs, I. \& Buckland, B., 1998, 'A theory of task / Technology fit in group support system effectiveness', MIS Quarterly 22(3), 313-334. https://doi.org/10.2307/249668 